\title{
Pengaruh Diethyl Ether Terhadap Torsi dan Daya Mesin Diesel Injeksi Langsung Berbahan Bakar Solar Campuran Jatropa
}

\author{
Faqih Fatkhurrozak $^{1}$, Firman Lukman Sanjaya ${ }^{2}$, Syarifudin $^{3}$, Syaiful ${ }^{4}$ \\ 1,2,3 Program Studi Teknik Mesin, Politeknik Harapan Bersama Tegal \\ ${ }^{4}$ Departemen Teknik Mesin, Universitas Diponegoro \\ 1,2,3 Jl. Mataram No.9 Pesurungan Lor, Kota Tegal, 52147, Indonesia \\ ${ }^{4}$ Jl. Prof. Soedarto No.13, Tembalang, Kota Semarang, Jawa Tengah, Indonesia \\ Email : faqih.fatkhurrozak@poltektegal.ac.id', sanjaya.firman51@gmail.com², masudinsyarif88@gmail.com³, \\ syaiful.undip2011@gmail.com ${ }^{4}$
}

\section{Info Naskah:}

Naskah masuk:14 Juni 2020

Direvisi: 3 Agustus 2020

Diterima: 13 Agustus 2020

\begin{abstract}
Abstrak
Konsumsi bahan bakar fosil yang semakin banyak, cadangan minyak yang semakin menipis dan semakin mahalnya bahan bakar telah memaksa untuk menggunakan bahan bakar alternatif. Diethyl ether (DEE) dapat dijadikan bahan bakar alternatif karena memiliki angka setana yang tinggi, viskositas yang rendah dan kandungan oksigen yang tinggi. Observasi ini dilakukan untuk mengetahui pengaruh penambahan Diethyl ether pada bahan bakar campuran solar-jatropa $20 \%$ terhadap torsi dan daya yang dihasilkan. Pengujian dilakukan pada mesin diesel injeksi langsung tipe 4JB1 dengan kecepatan konstan $2500 \mathrm{rpm}$. Volume DEE yang dipakai sebesar 5\%, 10\%, dan 15\% berbasis volume. Hasil pengujian menunjukkan kandungan jatropa $20 \%$ menghasilkan torsi dan daya yang lebih rendah dibandingkan solar murni (D100). Selain itu, penambahan DEE pada bahan bakar solar-jatropa20\% menghasilkan torsi dan daya yang rendah namun nilainya lebih tinggi dibandingkan bahan bakar solar-jatropa 20\%. Tren penurunan torsi dan daya tertinggi terjadi pada penggunaan bahan bakar DJ20 sebesar 0,0448\% saat pembebanan $25 \%$. Sedangkan penurunan torsi dan daya terendah terjadi pada bahan bakar DJ20DEE15 sebesar 0,0112\% dengan pembebanan 100\% dibandingkan bahan bakar D100.
\end{abstract}

\begin{abstract}
Increasing consumption of fossil fuels, depleting oil reserves and increasingly expensive fuels have forced the use of alternative fuels. Diethyl ether (DEE) can be used as an alternative fuel because it has a high cetane number, low viscosity, and high oxygen content. This observation was carried out to determine the effect of the addition of Diethyl ether on $20 \%$ diesel-jatropha fuel mixture to the torque and power produced. Tests carried out on a 4JB1 type direct injection diesel engine with a constant speed of $2500 \mathrm{rpm}$. The DEE volume used is $5 \%, 10 \%$, and $15 \%$ is volume-based. The test results show $20 \%$ jatropha content produces lower torque and power compared to pure diesel fuel (D100). Also, the addition of DEE to $20 \%$ diesel-jatropha fuel produces low torque and power but the value is higher than $20 \%$ of diesel-jatropha fuel. The highest torque and power reduction trends occurred in the use of DJ 20 fuel by $0.0448 \%$ when loading $25 \%$. While the lowest decrease in torque and power occurs in the DJ20DEE15 fuel by $0.0112 \%$ with $100 \%$ loading compared to D100 fuel.
\end{abstract}

*Penulis Korespondensi:

Faqih Fatkhurrozak

E-mail: Faqih.fatkhurrozak@poltektegal.ac.id 


\section{Pendahuluan}

Konsumsi bahan bakar fosil yang semakin banyak, cadangan minyak yang semakin menipis dan semakin mahalnya bahan bakar telah memaksa para peneliti dan produsen otomotif untuk menemukan sumber-sumber energi alternatif. Kebutuhan energi juga secara signifikan meningkat karena peningkatan pada jumlah, terutama di sektor transportasi. Badan Pusat Statistik (BPS) mencatat kenaikan jumlah mobil barang dari tahun 2015 yaitu sebesar 4.687.789 sampai dengan tahun 2018 sebesar 7.778.544 mengalami kenaikan sebesar $17 \%$.

Salah satu bahan bakar alternatif tersebut yaitu jatropa merupakan bahan bakar non pangan yang sudah banyak diteliti sebagai bahan bakar campuran bahan bakar diesel, sehingga diharapkan dapat mengurangi ketergantungan terhadap bahan bakar fosil [1],[2]. Hal itu juga diperkuat dari penelitian Syarifudin dkk, (2019) [3] jatropa memiliki kandungan cetane number yang hampir sama dengan solar. Namun secara umum penggunaan jatropa menurunkan performa mesin diesel dan meningkatkan emisi asap dibanding dengan solar murni [4],[5], [6].

Menurut Syarifudin dan Syaiful [7], penambahan alkohol pada bahan bakar mesin diesel dapat meningkatkan nilai torsi dan daya. Diethyl eter (DEE) merupakan salah satu jenis alkohol yang memiliki cetane number lebih dibandingkan bahan bakar solar dan memiliki kandungan nilai kalor yang lebih baik dibanding ethanol dan butanol [8].

Penelitian yang sama juga dilakukan oleh Karabektas dkk. [9] bahwa penggunaan DEE sebagai bahan aditif pada pengoperasian mesin diesel menghasilkan peningkatan efisiensi termal mesin dan konsumsi spesifik energi serta mengurangi emisi CO dan NOx. Trend yang sama juga terjadi penelitian S. Imtenan dkk [10], dimana emisi CO yang dihasilkan pada penambahan DEE sebagai additif bahan bakar mesin diesel mengalami penurunan.

\section{Metode Penelitian}

Bahan bakar yang digunakan pada penelitian ini adalah solar murni, jatropa dan diethyl ether (DEE). Bahan bakar solar murni diproduksi oleh PT. Pertamina, Tbk. Diethyl ether dan jatropa diperoleh dari toko kimia Indrasari, Semarang. Karakteristik utama bahan bakar tersebut di tunjukkan pada tabel 2.1. Persentase volume jatropa adalah $20 \%$. Sedangkan persentase volume diethyl ether yang diuji adalah $0 \%, 5 \%, 10 \%$ dan $15 \%$ dari volume diesel, secara berurutan disebut D100, DJ20, DJ20DEE5, DJ20DEE10, DJ20DEE15.

Tabel 1. Karakteristik bahan bakar

\begin{tabular}{clccc}
\hline No & \multicolumn{1}{c}{ Propertis } & Solar & Jatropa & DEE \\
\hline 1 & Angka Setana & 48 & 41,8 & 126,49 \\
2 & Kadar Air $(\% \mathrm{v})$ & 0,05 & 3,16 & 1,8 \\
3 & Viscositas (pada suhu $40^{\circ} \mathrm{C}$ & $2,0-$ & 3,23 & 0.22 \\
& (mPa.s)) & 5,0 & & \\
4 & Nilai Kalor $(\mathrm{MJ} / \mathrm{kg})$ & 45,21 & 37,97 & 33,89 \\
5 & Titik Nyala $\left({ }^{\circ} \mathrm{C}\right)$ & 60 & 198 & 45 \\
6 & Kandungan oksigen $(\%)$ & - & 10,9 & 21,6 \\
\hline
\end{tabular}

Eksperimen dilakukan dengan mesin diesel Isuzu 4JB1 injeksi langsung 4 silinder dengan kecepatan tetap $2500 \mathrm{rpm}$. Campuran bahan bakar solar, Jatropa dan DEE

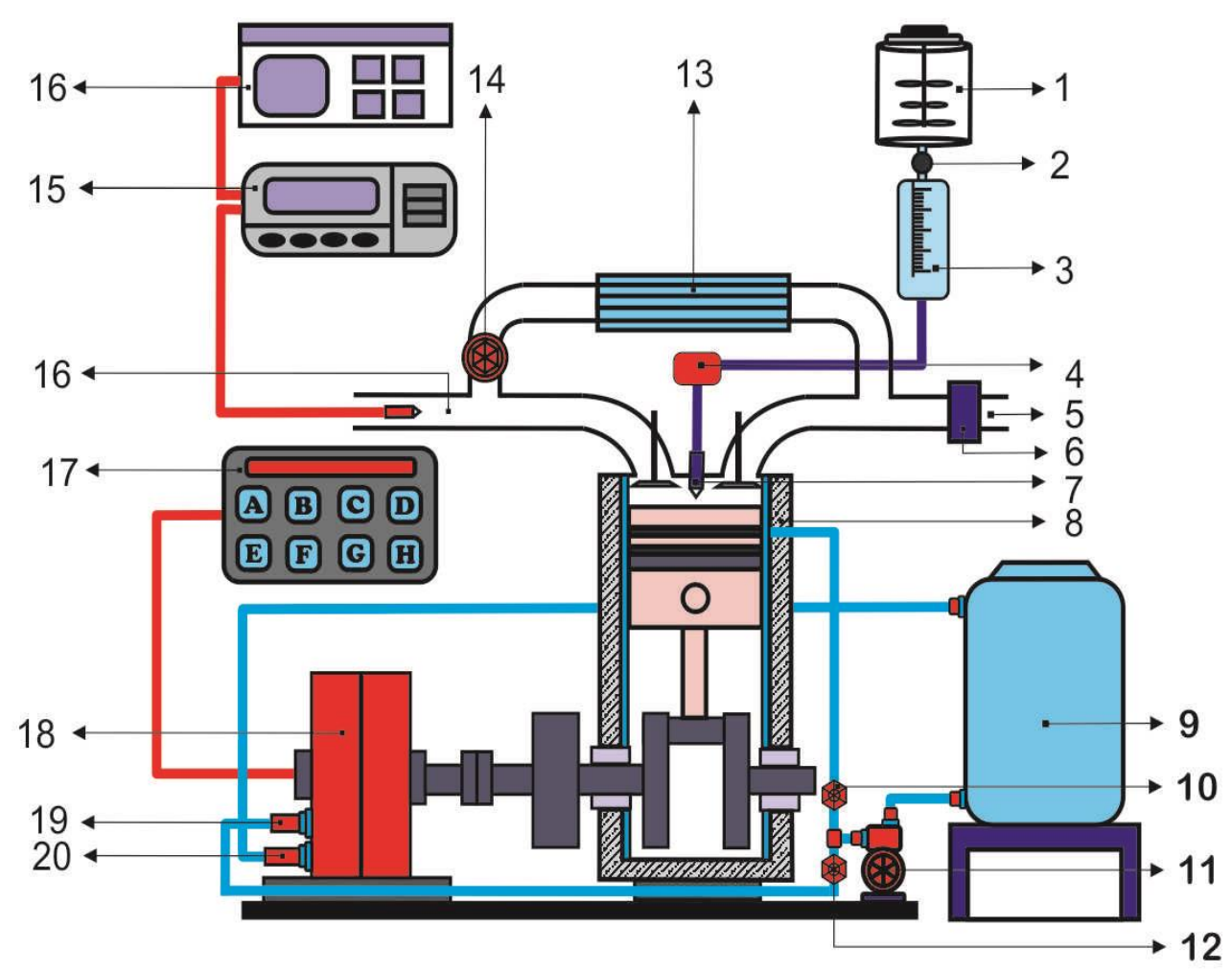

Gambar 1. Eksperimental Set-Up 
disiapkan sesuai dengan persentase pengujian sebelum percobaan dimulai. Karena sifat polaritas DEE yang tinggi sehingga sulit bercampur dengan solar, maka sebuah mixer (1) digunakan untuk untuk mendapatkan campuran bahan bakar yang homogen.

Posisi mixer ditempatkan lebih tinggi daripada mesin sehingga campuran bahan bakar akan mengalir ke mesin berdasarkan prinsip gravitasi dan juga dibantu oleh sebuah pompa bahan bahan (fuel feed pump) yang terpasang pada mesin. Sebuah buret (2) dengan sebuah katup bahan bakar (3) dipakai untuk mengukur konsumsi bahan bakar, dimana setiap $30 \mathrm{ml}$ diukur waktunya melalui sebuah gelas ukur yang dihitung menggunakan stopwatch yang selanjutnya menuju pompa injeksi bahan bakar (4) dan disemprotkan oleh injector (7).

Sebuah tachometer (17) digunakan untuk mengukur putaran mesin yang diukur oleh sebuah proximity sensor. Untuk mengukur daya yang keluar di gunakan dynamometer (18) merk Dynomite Land\&Sea. Untuk mengukur torsi mesin, poros mesin dikopel dengan sebuah dynometer yang dibebani dengan media air. Variasi pembebanan mesin dilakukan melalui pembukaan katup aliran air (10) ke dynamometer sebesar 25\%, 50\%, 75\% dan $100 \%$. Air yang ditampung pada tanki air akan dialirkan oleh sebuah pompa (11) menuju saluran inlet (20) pada dynamometer dan langsung dibuang (tidak disirkulasikan) (9).

Besarnya torsi yang timbul dibaca oleh sebuah strain load sensor yang terpasang pada lengan torsi di dynamometer akibat pembebanan dan akan ditampilkan pada load display (17). Eksperimen dilakukan pada putaran mesin yang tetap yaitu $2500 \mathrm{rpm}$ dengan variasi campuran bahan bakar.

\section{Hasil dan Pembahasan}

\subsection{Torsi mesin diesel berbahan bakar solar-jatropha- DEE}

Penggunaan bahan bakar solar dan jatropa menghasilkan nilai torsi yang lebih rendah dibandingkan solar murni (D100). Rendahnya nilai kalor dan tingginya viskositas dari bahan bakar campuran mempengaruhi buruknya karakteristik pembakaran [7], [11]. Akan tetapi, ketika penambahan DEE pada bahan bakar solar campuran jatropa 20\%/DJ20 menghasilkan nilai torsi yang lebih tinggi dibandingkan DJ20 meskipun masih lebih rendah daripada D100.

Kadar oksigen yang tinggi, cetane number yang tinggi dan viskositas yang lebih rendah dibandingkan bahan bakar DJ20 menjadi faktor utama tren meningkatnya nilai Torsi [12],[5]. Hasil yang sama juga terjadi pada penelitian Firman dkk [13]. Pada Gambar 2 merupakan grafik hasil pengujian torsi dengan variasi bahan bakar solar-jatropaDEE. Jatropa yang digunakan dalam penelitian ini sebesar $20 \%$ berbasis volume. Sedangkan DEE yang digunakan sebesar $5 \%, 10 \%, 15 \%$ berbasis volume.

Penurunan nilai torsi tertinggi akibat penggunaan bahan bakar campuran terjadi pada bahan bakar DJ20 sebesar $0,045 \%$ dengan pembebanan $25 \%$ dibanding solar murni (D100). Sedangkan penurunan nilai torsi terendah terjadi pada bahan bakar DJ20DE15 sebesar 0,112\% dengan pembebanan $100 \%$ dibanding solar murni (D100). Adapun nilai torsi tertinggi terjadi pada bahan bakar DJ20DE15 sebesar 139,728 N.m dengan pembebanan $100 \%$ dan nilai torsi terendah terjadi pada bahan bakar DJ20 sebesar 92,973 N.m dengan pembebanan 25\% dibanding diesel murni (D100).

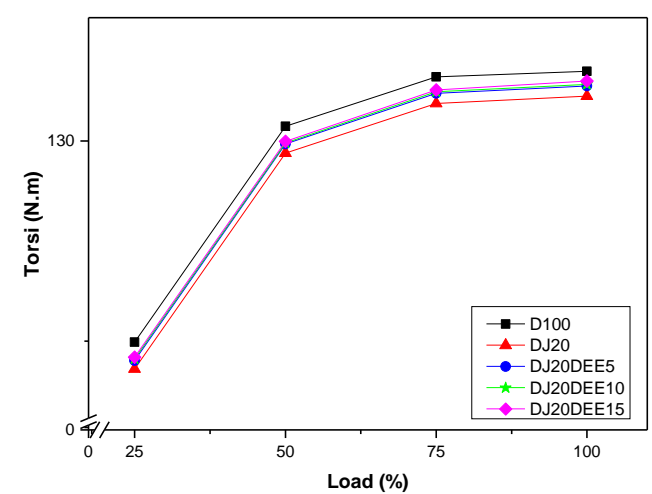

Gambar 2. Pengaruh variasi bahan bakar diesel- jatropa-DEE terhadap torsi

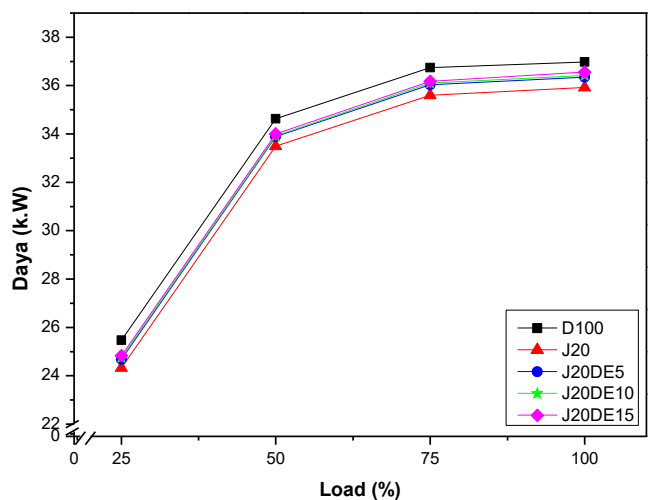

Gambar 3. Pengaruh variasi bahan bakar diesel-jatropa-DEE terhadap daya

\subsection{Daya mesin diesel berbahan bakar solar-jatropha- DEE}

Penggunaan bahan bakar solar dan jatropa $20 \%$ menyebabkan nilai daya mengalami penurunan dibanding solar murni. Hal ini dikarenakan rendahnya nilai kalor, dan tingginya viskositas pada jatropa menyebabkan pembakaran yang buruk [11], [7]. Hasil yang berbeda didapat ketika alkohol DEE ditambahkan pada bahan bakar solar campuran jatropa 20\%. Viskositas yang rendah dan oksigen yang tinggi pada DEE meningkatkan nilai torsi dan daya mesin diesel meskipun masih lebih rendah daripada bahan bakar solar murni (D100) [12]. Pada Gambar 3 adalah hasil pengujian menggunakan variasi bahan bakar solar- jatropaDEE.

Penurunan tertinggi pengujian daya terjadi ketika menggunakan bahan bakar DJ20 sebesar 0,0448\% dengan 
pembebanan $25 \%$ daripada D100. Sedangkan penurunan pengujian daya terendah terjadi pada bahan bakar dengan kandungan DEE sebesar $15 \%$ yaitu $0,0112 \%$ dengan pembebanan $100 \%$ daripada D100. Adapun nilai daya tertinggi terjadi pada bahan bakar DJ20DEE15 sebesar $36,562 \mathrm{~kW}$ dengan pembebanan $100 \%$ dan nilai brake power terendah terjadi pada bahan bakar DJ20 sebesar $24,328 \mathrm{~kW}$ sebesar $24,328 \mathrm{~kW}$ dengan pembebanan $25 \%$ dibanding diesel murni (D100).

\section{Kesimpulan}

Berdasarkan kajian eksperimental yang dilakukan pada penelitian ini, penggunaan bahan bakar solar campuran jatropa 20\% menghasilkan torsi dan daya yang lebih rendah dibandingkan bahan bakar solar murni (D100). Penurunan nilai torsi tertinggi pada penggunaan bahan bakar ini mencapai $0,0448 \%$. Namun, penambahan DEE pada bahan bakar solar campuran jatropa memperbaiki torsi dan daya mesin diesel. peningkatan akibat kandungan DEE tertinggi terjadi pada bahan bakar DJ20DEE15 yaitu sebesar 0,0112\% saat pembebanan 100 .

\section{Daftar Pustaka}

[1] Dubey, P., Gupta., "Title Jatropha bio-diesel production and use Authors Katholieke Universiteit Leuven, Division Forest, Nature and Landscape, Celestijnenlaan 200 E Box 2411 , BE-3001 Leuven , Belgium World Agroforestry Centre ( ICRAF ) Head Quarters, United Nations Avenue, P . O . Box 30677 , Nairobi, Kenya FACT Foundation, Horsten 1 , 5612 AX Eindhoven , The Netherlands Katholieke Universiteit Leuven, Division Agricultural and Food Economics, Willem de Croylaan 42 Box 2424 , BE3001 Leuven, Belgium World Agroforestry Centre ( ICRAF ) Regional office for South Asia, CG Block, 1 st Floor, National Agricultural Science Centre , Dev Prakash Shastri Marg , Pusa , New Delhi - 110," vol. 32, no. 12, pp. 1063 1084, 2008.

[2] Chandra, V., Singh, K., Shankar, J., Kumar, A., Singh, B., and Singh, R. P., "Jatropha curcas : A potential biofuel plant for sustainable environmental development," Renew. Sustain. Energy Rev., vol. 16, no. 5, pp. 2870-2883, 2012.

[3] J. R. Mesin, "Daya dan Emisi Jelaga dari Mesin Diesel Berbahan Bakar Solar-Jatropa- Buthanol," vol. 14, no. 3, pp.
$142-145,2019$

[4] Senthilkumar, R., Ramadoss, K., and Manimaran, R., "Methods used in Diesel Engine," vol. 13, no. 1, 2013.

[5] Fatkhurrozak, F,. Syaiful,. "Effect of Diethyl Ether ( DEE ) on Performances and Smoke Emission of Direct Injection Diesel Engine Fueled by Diesel and Jatropha Oil Blends with Cold EGR System Effect of Diethyl Ether ( DEE ) on Performances and Smoke Emission of Direct Injection Diesel Engine Fueled by Diesel and Jatropha Oil Blends with Cold EGR System,” I. O. P. C. Series and M. Science, 2019.

[6] Syarifudin., Syaiful., "Pengaruh Penggunaan Energi Terbarukan Butanol Terhadap Penurunan Emisi Jelaga Mesin Diesel Injeksi Langsung Berbahan Bakar Biodiesel Campuran Solar," vol. 10, no. 01, pp. 18-22, 2019.

[7] Syarifudin., Syaiful., "Performance and soot emissions from direct injection diesel engine fueled by diesel-jatrophabutanol-blended diesel fuel Performance and soot emissions from direct injection diesel engine fueled by diesel-jatrophabutanol-blended diesel fuel," C. Series, 2020.

[8] Rakopoulos, D. C., "Combustion and emissions of cottonseed oil and its bio-diesel in blends with either $\mathrm{n}$ butanol or diethyl ether in HSDI diesel engine," Fuel, vol. 105, no. 2013, pp. 603-613, 2020.

[9] Karabektas, M., Ergen, G., and Hosoz, M., "Effects of the blends containing low ratios of alternative fuels on the performance and emission characteristics of a diesel engine," vol. 112, pp. 537-541, 2013.

[10] Imtenan, S., Masjuki, H. H., Varman, M., Fattah, I. M. R., Sajjad, H., and Arbab, M. I., "Effect of n- butanol and diethyl ether as oxygenated additives on combustion emission-performance characteristics of a multiple cylinder diesel engine fuelled with diesel - jatropha biodiesel blend," Energy Convers. Manag., vol. 94, pp. 84-94, 2015.

[11] Tuan, A., Tuan, A., and Pham, V. V., "A core correlation of spray characteristics, deposit formation, and combustion of a high-speed diesel engine fueled with Jatropha oil and diesel fuel," Fuel, vol. 244, no. February, pp. 159-175, 2019.

[12] Ibrahim, A., "Performance and combustion characteristics of a diesel engine fuelled by butanol - biodiesel - diesel blends," vol. 103, pp. 651-659, 2016.

[13] Sanjaya, F. L., "Pengaruh Penambahan Butanol sebagai Campuran Bahan Bakar Premium terhadap Torsi dan Daya Mesin Bensin dengan Sistem EGR,” vol. 1, no. 1, pp. 7-10, 2020. 